physicsworldarchive.iop.org

\title{
Decline increasing: normality declining
}

Robert Eason, Chris Nash

From

Physics World

April 1998

(C) IOP Publishing Ltd 2009

ISSN: 0953-8585

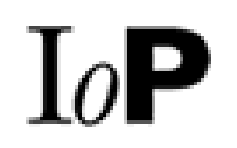

Institute of Physics Publishing

Bristol and Philadelphia

Downloaded on Fri Jun 12 12:35:12 BST 2009 [152.78.73.101] 


\section{Decline increasing: normality declining}

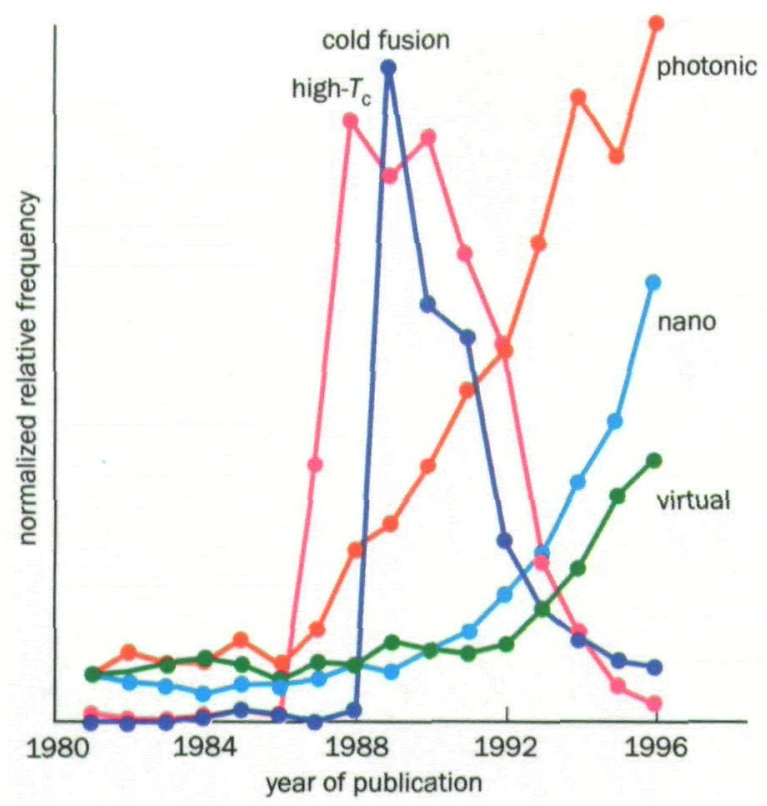

Past their peak - high- $T_{\mathrm{c}}$ and cold fusion are now passé

Information is the currency of scientific pursuit, and its immediate access is a presumed universal right to today's students. No longer must the information-seeker spend hours, days and even weeks trawling through Current Contents, as all information is now freely available at the click of a mouse. The fruitless trudge, searching for obscure journals that your library doesn't even take, and the fun to be had from sending uninitiated students on such useless errands, are both sadly gone forever. We are all part of the universal information network, and we have never had it so good.

Although the authors learned how to access the secrets of the Bath Information and Data Services (BIDS) database several years after everyone else at this university, we are now hooked: a return to the days of manual searching is both unthinkable and depressing. But such automated search facilities allow you to do much more than merely finding scientific references and the like. The ability to quiz the database for any articles that contain your favourite choice of rude, silly or double-meaning words is too good an offer to turn down. In the blink of an eye, the answer comes back, and those of furtive or fertile minds are changed forever. About one million papers are scanned by BIDS each year, covering all of the journals you could desire, and searching by contents of title, abstract or authors, is completely trivial - even for some of us older practitioners of the scientific art.

An excellent example of such search frivolity recently appeared in the journal Nature (1997 385 480), which featured a letter by Simon Friedman and Jens Karlsson from the universities of California and Illinois in the US. They had interrogated their local medical database (Medline) for the incidence of the word "novel" in the title or abstract of papers published over the previous 19 years. The rate of "novel" appearance followed an almost exactly exponential growth rate: by the year 2020 , they jokingly predicted, novelty must surely be universal.

Thus inspired, we accessed BIDS in an attempt to turn up something hopefully more improbable or obscure. We started with a repeat of the previous "novel" search, and - no surprise - saw a similar trend. "Novel" is too tempt-
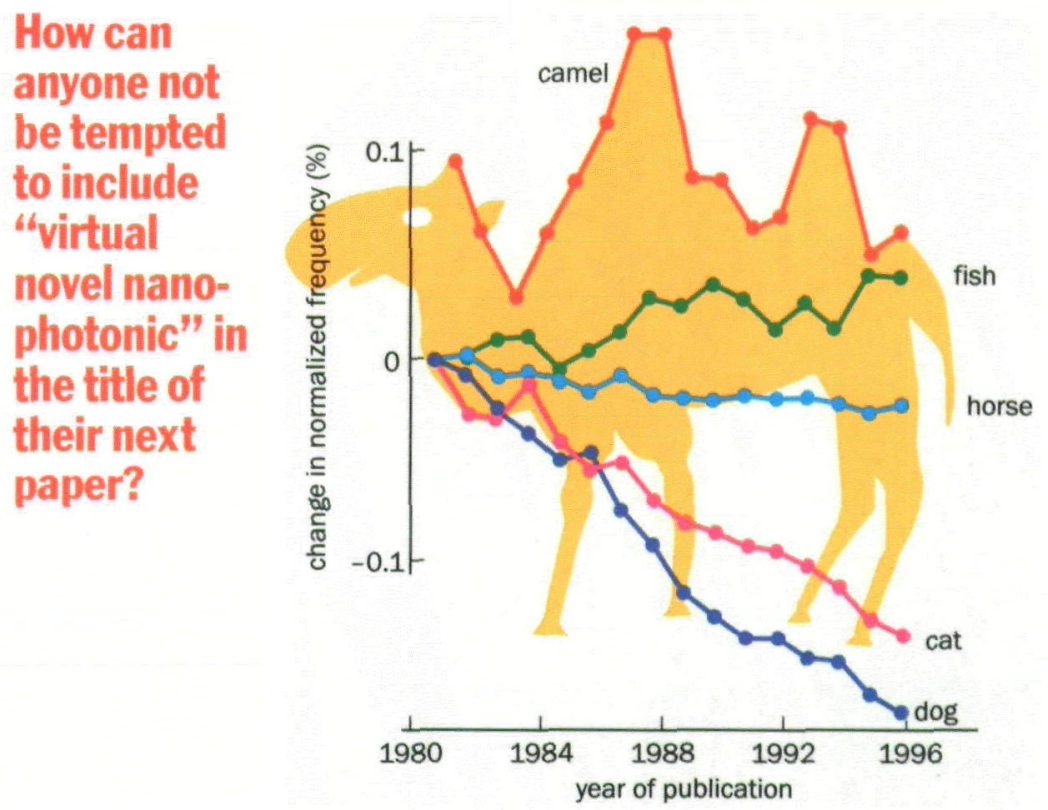

Evolution - cats are dying out, but camels are over the hump

ing a word to reject: how can any of one's research not be novel? But not so with "new" or "normal". We found an overwhelming preference for novelty over newness. We also noted that while the Nature letter showed that more than $2 \%$ of all Medline listed papers are novel, less than $1 \%$ of Science papers fall into this category. But to be fair, we only searched under title, and a search of "title plus abstract" can yield different results.

So now we know how to play the game, what's next? Certain words have sprung up within the scientific community like puffballs. Not there yesterday, but today you can't move without falling over them. Typical examples include "photonic", "nano-" and "virtual". And such searching has a genuine added bonus. How can anyone not be tempted to profitably employ tactical restructuring, and include the phrase "virtual novel nanophotonic" in the title of their next paper? But be careful; words like "high- $\mathcal{T}_{c}$ " and "cold fusion" have now peaked. Their use is definitely passé. Avoid them at all costs.

Adjectives provide another invaluable source of good search material, and now we begin to see a more sinister picture emerging. Qualifiers such as "unique", "innovative" and "wide" are on an upwardly mobile trend. But how can things get progressively more unique? And although "increas*" is increasing we found that "decline" isn't declining, while the frequency of "constant" isn't constant, unlike the frequency of "frequency". It is just as well that "level" turns out to be on the level!

In desperation to make sense of it all, we finally sought help from the animal kingdom. "Cat" and "dog" are clearly falling, while "fish" are swimming against the tide. And as for "camel", what more need we say?

So where does all of this leave us? Having used up all of those valuable hours, days and weeks searching BIDS, to save weeks, days and hours, we are left in a net no-timegain situation. Which reminds us, we must just search under "situation"... 